\title{
Reader Stance and a Focus on Gender Differences
}

\author{
Feng-ming Chi \\ Dept. of Foreign Languages \& Literature, National Chung Cheng University \\ 168 University Road, Min-Hsiuhg, Chia-Yi 621, Taiwan \\ Tel: 886-5272-1108Ｅ-mail:folfmc@ccu.edu.tw
}

The paper is financed by National Science Council, Taiwan

\begin{abstract}
The purpose of this paper, drawing data from a large research base, was to investigate how and why Taiwanese EFL (English as a Foreign Language) male and female university students responded to feminist texts differently. These participants were taking an elective course titled Gender and Reading while this research was conducted. Weekly reading journal entries were used for data analysis. Idea units were first used to categorize participants' journal entries; relevant idea units were grouped together, and then organized into stances for discussion. Four stances-textual, evaluative, reflective, and resistant-were generated for interpretation. Comparative content analysis was then applied to contrast male and female participants' stances while responding to feminist texts. Some pedagogical implications are suggested for classroom practice.
\end{abstract}

Keywords: Reader stance, Reflective stance, Resistant stance

\section{Introduction}

One factor that affects a reader's understanding and interpretation of a literary work is a reader's stance, or focus of attention. Stance in literacy events is defined as a reader's ideological orientation or perspective and so linked with reader's openness or "responsive understanding" to indeterminacies and ambivalence inherent in discourse and social relationships (Many, 1994; Many \& Cox, 1992). In inferring possible meanings, the reader must apply his/her stance-i.e., ideological orientation or perspective. When adopting a stance, a reader infers those meanings consistent with their beliefs, attitudes, or disciplinary orientation. Readers may adopt a stance whereby they suppress exploration of multiple meanings or "responsive understanding," in which they actively explore multiple meanings (Beach, 1994, 1997; Corcoran, 1992).

Unfortunately, previous research on reading English as a Second/Foreign Language (ESL/EFL) has seldom examined the role of meanings inherent in readers' ideological stances. Language learning and knowledge acquisition in ESL/EFL classes are always viewed as two separate entities, of which linguistic components are major focuses of English instruction (Chi, 2006). A crucial step to assist ESL/EFL students to realize their knowledge of words can also enhance their knowledge of other worlds gained through exercise that stresses real interaction with the target language holds another benefit, since learners vary in mode of expression and rhetorical strategy. For reading in ESL/EFL, modes involve learners not only achieving propositional and procedural knowledge of language structure and norms, but also acquiring beliefs, values, and attitudes about self, others, and text (Cochran, 1996; Mackie, 1999).

Gender issues in classrooms appear in a growing body of research. Lloyd (1998) and Maher (2002) point out many implications of gender bias in classrooms and suggest that these contribute to loss of self-esteem and academic security for girls. Adolescence is also a time when the lives of boys and girls become even more sex-differentiated. Taylor (1993) strongly insists that social construction of gender is an active and ongoing process; teachers must supply materials with alternative versions of femininity-those more helpful to females in developing a sense of self and their future as women. Such text will more likely provide both sexes with chances to "bump up against ideologies" and try on diverse forms of agency, making it necessary to widen the range of discourse available to girls, thereby extending a repertoire on which to draw in constructing their femininity. Singh (2008) and Wayne (2004) further advocate that it also vital to broaden the range of discourse available to boys in an effort to expand possibilities for constructing their masculinity. A means of widening the range is to offer reading material facilitating a feminist reading and offers alternative forms of female and male agency. Yet merely providing texts is unlikely to suffice in helping students read texts differently. Girls are members of a society that has historically devalued female's experiences and concerns; both sexes likely need support and guidance in attempting to read against stereotypical roles of boys and girls. More importantly, feminist texts derive added value from new questions emerging with girls put "at the center" of analysis. Barrs (2000) also argues the importance of social factors during adolescence and pinpoints that this is a critical time for adolescents to construct a sense of personal identity. It is a time for trying on selves, for reflection, self-awareness, and self-definition. 
Alcoff (1988) argued that gender is not a point starting, not a given, but a construct, formalizing discourse in some non-arbitrary way through a matrix of habits and practices. Reading is a way of knowing, not simply decoding or what readers already know; only where there is language is there word. Reader gender--a myriad of experiences, attitudes, ideas, memories, and feelings before the reading event--is reconstructed in the act of reading. If the text is one that should be resisted, becoming can mean either alienation or active resistance. If the text should be embraced, becoming can mean either passivity or active acceptance (Cherland \& Anson, 1992). Students' efforts to read against the grain may be influenced by type of text read. These concerns led the researcher to peruse the feminist texts and discover female protagonists/heroines strong, active, resourceful, independent, and capable of solving their own and others' dilemmas. When fictional characters contradict or confront societal norms for females, how do EFL university students respond? How do non-traditional fictional females appeal differently to male and female university students? Considering these discoveries, the researcher concluded that the most natural way to answer these inquiry questions about how young adult collegians responded to feminist texts was to go to the students themselves.

\section{Method}

\subsection{Research Setting and Participants}

Setting for this study was a national university, a campus of 12,000 students, located in the middle of Taiwan. Admission requirements included passing the competitive national entrance examination. Five male and five female participants were voluntary to take part in this paper as focal participants, who were willing to reveal their detailed journal entries and oral interviews for the public. These ten focal participants were all English majors, 6 juniors and 4 seniors. They all enrolled in an elective course titled "Gender and Reading," a 17-week course meeting three hours a week during the time of this study. In general, these participants had been exposed to at least six years of English in high school and two or three years at university level, also in Taiwan, and they also hailed from similar cultural and language learning backgrounds.

\subsection{Selection of Feminist Texts}

Texts selected challenged students to read and discuss gender equality issues. Choice of text for this study was based on several criteria: (1) content unfamiliar to participants; (2) potential for multi-layered interpretation; and (3) concept of woman's self-awareness. Appendix 1 presents a list of texts extracted for the current paper.

\subsection{Data Collection Procedures}

Two types of data, the participants' weekly journal responses and semi-structured oral interviews, were used for the current paper, as described below:

2.3.1 Reading Journal Entries: Participants' weekly journal entries were a vital data source, since enrollees in the course were all requested to take part in journal writing throughout the semester. Though students were urged to write as many journal responses as possible, typically they wrote at least one per week. A journal response usually consisted of one to several paragraphs; most were composed on word processors as the semester progressed, though several participants sometimes wrote by hand. At the outset of the term, students were advised to write responses in journal form to any reading material and/or classroom discussion, with reference to gender equity issues. They were informed that the purpose of journal writing was communication and reflection; for that reason journals would not be corrected. As for grading, they were notified that minimum credits would be awarded to anyone submitting journals on time, maximum credits based on quality and quantity of journal writing. The teacher (researcher) would read journals and respond to content of students' writing as if replying to a letter from a friend. No corrections or suggestions pertaining to quality of writing or even contents or ideas were made.

2.3.2 Semi-structured Oral Interviews: Goals of the semi-structured oral interviews included finding out how participants reacted to text, peers, and class discussion. Those interviews likewise afforded the researcher chances not only to share transcripts with participants of interpretations of data but also to ask for clarification about specific reflections. This gave participants occasion to review their interview transcripts and to alter, amend and/or reiterate previously stated views. Sharing of transcripts and early interpretations of perspectives with participants conforms to Lincoln and Guba's (1985) practice called member-checking; they claim researchers have an obligation to represent subjects accurately and fairly, that member-checking boosts trustworthiness and credibility of research. Each participant was interviewed twice; at the middle and end of the term. Both interviews were tape-recorded and transcribed verbatim by the two research associates.

\subsection{Data Analysis Procedures}

In data analysis, idea units were first used to categorize participants' journal responses. Each paragraph was coded and analyzed as an idea unit; relevant idea units were moved, grouped together, and then organized into a stance as a discussion pattern. Four stances (textual, evaluative, reflective, and resistant), were generated to compare how males and females responded to feminist texts. As for oral interviews, data relevant to stances were first underlined and coded, 
then moved to their relevant stance for data analysis and interpretation. A total of 131 identifiable idea units were coded from two divergent types of data written by participants, 86 relating to the four stances. Comparative content analysis was then applied to gauge how males and females responded differently to reading texts and in-depth discussion of such differences is illustrated below.

\subsection{Credibility}

To ensure credibility of analysis, transcripts were first coded by the researcher, then by two EFL instructors. The researcher discussed the coding system with these teachers and displayed two or three samples of each theme, any discrepancies discussed and resolved. Data igniting disagreement between us were discarded from the data pool. After lengthy conversations and negotiations, inter-coding agreements we eventually reached were $84 \%$ between the researcher and EFL teachers, $85 \%$ between the EFL teachers themselves.

\section{Results and Discussion}

Discussion of stances should not, however, be construed as representing necessarily distinct entities. Separation of a particular sequence of these stances, then, reflects more of the researcher's rhetorical needs than of natural processes participants undergo along the path of reading and responding to feminist texts.

\subsection{Textual stance}

Beach (1994) defines "textual stance" as readers' knowledge of how different language functions impact making of meaning. In this study, textual stance focused on participants utilizing their knowledge of discourse organization, knowledge of the author, and textual information to make sense or meaning of texts. In order to make sense of feminist texts, participants were apt to elaborate upon the texts locally, based on linguistic components like words or phrases. Titles, metaphors, and author's writing style were also employed as textual clues as resources for making sense and meaning. However, reading a feminist text spawns reading disjunctions that emerge from confusion, ambiguity, inconsistency, and even absurdity, so relationships between reader and text or reader and author grow stressful and aversive. Such situations occurred very obvious to participants when they read the text "Becoming a Mother," since no participant had parental experiences.

An interesting phenomenon related to gender differences emerged whenever male and female subjects encountered parts they failed to understand. Some participants recorded their lack of understanding, resulting in confusion about aspects of the reading text. Such situations became especially obvious when they read the essays on maternity, since none of them had had such experiences in their previous life. Their knowledge about and belief in maternity and motherhood came from their personal investigation and others' telling. These vignettes below glean from Jim's and May's journal responses upon encountering the issue of maternity.

Extract A (Jim, "Becoming a Mother")

I don't know what to write about this week. As a male I have no experience as another. I don't quite understand why my classmates said it means big pressure to be a mother, so I will write something about what I read from the newspaper for this assignment.

Extract B (May, "Becoming a Mother")

Since I am not a mother, I don't know how a mother feels about the role of a mother. As I know many girls are dream of being one. As we discussed in class, maybe that's because the media portrays motherhood in a very positive way. That's why we never think about how much burden a mother carries or whether we want to be a mother or not. The article makes me start thinking whether I want to be a mother or not.

Extract A manifests Jim's attempt to shy away from lack of understanding on maternal issues by illustrating his own experiences. In contrast to Jim, May in Extract B not only stated what she did not understand but also tried to interpret the part she could not fully understand. Female participants like May seemed to engage with text, offering possible interpretation of passages rather than only stating their confusion. Males like Jim merely stated their lack of experience or understanding, then disengaged from the text. Results presented in this study support Flynn's (1986) research, which cites how "male students sometimes react to disturbing stories by rejecting them or dominating them, a strategy, it seems, that women do not employ. Females often arrive at meaningful interpretations of stories because they more frequently break free of the submissive entanglement (p. 285)." Males, as indicated in Extract C, reacted differently from female participants.

Extract C (Jack, "Becoming a Mother")

I am not a mother, so I have no right to respond to the reading text this week, "Becoming a Mother.' Before class was dismissed, you [the professor] once mentioned "castration anxiety." I think it is an interesting term and thus look it up in feminist books. At last I got extra knowledge and concluded "fetishism" is the by-product of "castration anxiety." A little boy's castration anxiety begins when he sees that his mother has no penis. He thinks the mother was castrated and 
grows anxious about his own penis. Originally the boy regards his mother as a phallic mother, but now she is reduced to the woman by the lack. The boy is forced to accept gender difference from the original un-differentiation. Consequently, fetishism is recognition plus disavowal of female castration. This is what I get out from the textbook, and I'm glad to share it with you.

As shown in Extract C, so as to avoid being directly detached from the reading text, Jack instead switched his responses to clarify the term "castration anxiety." In sum, both male and female participants took a textual stance to comprehend and interpret reading text, but when it comes to how they approached segments where they lacked understanding or experience, gender differences did arise in their journal responses. When using various strategies to deal with their lack of understanding, divergent approaches were selected by the two sexes. Males were more likely to react passively, demonstrating confusion and/or frustration, then disengaging from the text. In contrast, female participants tended to state confusion and then offer possible interpretations of a difficult part. They took the risk that their ideas may be faulty, but were thereby curious about possibilities and engaged with texts. They did not show the same frustration males exhibited. Both genders used other tacks of using questions, re-reading, and physical affect. In this view, our study supports Flynn (1986): “a pattern of dominance was evident in some of the men's responses and more women were able to resolve the tensions in the stories and form a consistent pattern of meaning. The dominant reader is often a detached reader; the text is not engaged, and so the reader feels little empathy for the central characters" (pp. 272-273).

\subsection{Evaluative Stance}

Textual meaning can possibly be made or changed as well as extended and enriched at every new moment and in each new environment. As the class continued their readings on gender issues, participants constantly re-defined texts, re-framed thoughts and beliefs, re-constructing their personal experiences and knowledge of the world and of language. Such a process lends readers opportunities to continually revise their existing knowledge. Evaluative stance afforded chances to revisit a text, read discuss, and finally re-examine their comprehension and interpretation. Ongoing reading text grew more understandable for readers astute enough to detect their own previous thoughts; it became powerful when they connected earlier text with the present one and related these to prior experiences.

Gender differences seem to exist with respect to both sexes' emotionally evaluative responses to characters and to situations: female and male readers exhibited emotional reactions to events, and therefore showed their engagement with the texts. Excerpts from response journals indicate that participants' emotional responses were essential to them as they drew themselves into a text, and caused them to relate their own feelings to those of the characters. Many female subjects revealed emotional evaluations such as "It is an interesting story to read, "I like the woman [in 'The Office']," whereas no male reacted to any text with such emotionally evaluative discourses as "interesting" or "fascinating." Moreover, female participants focused on their emotional reactions to characters involved in an event, rather than the event itself. Simpson (1996) discovered how "girls regularly empathized with characters and related events to their own feeling," while "boys would discuss plot, focus upon the action, and challenge the possibility of particular events in the story" (p.271). Ruby and Dean exemplify how the sexes responded to reading texts.

\section{Extract D (Ruby, “The Frog Princess”)}

I loved the end of the story very much. The princess and prince did not match with each other and they were unhappy while living together. The princess 'loved her husband but couldn't adopt herself to his lifestyle." "She had tried and failed."...

\section{Extract E (Dean, "White Riding Hood")}

Page 16 mentioned that the grandmother chopped up the hunter's body into manageable piece and strewed them in the forest for wolves to eat. To me, that is somewhat cruel and bloody. I don't agree that violence can resolve all the problems. Once in a while women grouse that men always use violence to solve problems. Thus, when it is women's turn to get to the power, it is not smart to make the same mistakes. I suggest that using peaceful ways when women are fighting their rights. I don't mean to speak for men's rights, but if women fight with violence, people get sick of it.

As data suggested from the current study, more female than male responses revealed empathy with characters, whereas more male than female participants responded with empathy toward situations rather than about characters. The extracts presented above indicate how gender differences influence journal responses. When a reader is "touched" or "moved" in a certain way, true engagement with a text like compassion, sympathy, or even anger are naturally developed. Empathy is strong concern for characters as people-emotional involvement comprising reactions to authors, observers, and other characters" (Bantmeier, 2003). Many female participants repeatedly displayed empathy for characters in the readings. As for male participants, Dean is the only one who responded to the reading text with somewhat emotional evaluation. Extract E indicates how Dean's responses are similar to Cherland and Edelsky's study (1993): boys were "more inclined to read literature in terms of both plot and event" (p.145). Unlike Evans' research (1996), in which "boys emphasized specific plot events in the story, but did not address the internal motivation or reasons behind the 
events" (p.187), Dean in the current study, aside from addressing his internal response to the "White Riding Hood" grandmother's cruelty, also flaunted his evaluative stance by integrating his claiming voice on gender equity.

\subsection{Reflective Stance}

Reflection provides chances for learners to integrate self and knowledge as one entity. Beach (1998) and Many (2001) strongly advocate autobiographical responses for interpreting texts, which in turn promotes text interpretation and knowledge acquisition. Reflective stance in this study refers to participants' ability to use self as an instrument for learning. That is, reflection is defined as a self-applied process of learning, use of self as an active sign in learning (Chi, 2008). In this sense, reflection is viewed as an action which allows participants to turn personal experiences into learning by critically re-examining or casting their past experiences into some new context (Lloyd, 1998; Taylor, 1993). In relaying personal experiences as a reflective stance, both male and female participants employed first-person narration. By using "I" throughout their explanations, readers may feel closer to the event and gets the sense that the writer is being sincere; thus, use of "I" as a personal voice ("I think," I believe," "I wonder,") signifies a writer's involvement in a given subject. Yet personal narrative voice presented herein reveals gender differences in using a reflective stance to project the subjects' voice in highly disparate ways. While identifying with characters in readings due to similarities or differences from self, males tended to criticize what characters did in a story, then tell how they would act differently. In female participants' responses, similarities between characters and self appeared more than differences, as seen from Linda's and Odey's journal responses.

Extract F (Linda, "Everyday Use")

In my opinion, Dee doesn't identify with her black culture; she considers white culture superior to the black. This also occurs in Taiwan. Many Taiwanese will worship foreign culture, movies, music, etc....This case indicates lack of confidence in our own culture, which we see as inferior...I have to confess I have a tendency to worship foreign things like culture and movies. When I meet white foreigners, western people, I am very happy and even feel excited to talk to them, while I am afraid of Thai or Vietnamese laborers. For me, they are horrible and dangerous because they come from developing countries. Compared with western people, they are inferior, so I look down on them. I was not even aware of this until I read "Everyday Use." I think Ruby is right; maybe in some way, we are just like Dee, albeit not conscious of this. Much worse, many TV and MTV programs depict white as superior to black, man superior to woman.

\section{Extract G (Odey, "The Office”)}

After reading and discussing "The Office" in class, I feel male and female are educated differently. We males are educated to protect girls; I see it is my responsibility, and girls also want to be protected and cared. If I don't do that, my girl friend will complain about me. The writer could tell the landlady so that the problem may be solved. Girls always just complain without taking any action.

Influenced by their reading of "Everyday Use," several female participants like Linda (in Extract F) revealed irrational fears and deeply held prejudices on sexism or racism. They pursued a discussion of race as their group talked about their fear of the foreign laborers in Taiwan, and expanded that discussion to include people with differences (e.g., blind, learning disabled, elderly, poor). Once again, it was girls who expressed feelings (fear of being old or ugly, fear of being touched by a boy, etc.). The girls revealed that they felt unsure, tentative and anxious about these issues in their own lives. Linda in Example F even tried to compare her own experiences with those of foreigners. She sees similarity rather than difference as the dominant feature of Odey's journal responses, as indicated in Extract G. Linda even tried to think about how television and advertising have had great impact on gender stereotypes. From a gender standpoint, girls related affectively to story characters, identifying and expressing feelings of fear, sadness, pity, or anger; boys only took the reflective stance as a way to defend their voices. An excerpt from Jack's journal response (Extract H) illustrates such defensive voices.

\section{Extract H (Jack, "The Office”)}

[Today I said I would quit a job if my wife wanted me to stay home and take care of the children.] I feel so depressed upon hearing that "I am a person without my own opinion." What wrong doings do I do? Why is my consideration regarded as having no opinion? If today I say, "You quit the job," what would all of you say? "Oh, you are so dominant"? I just feel unfair and wonder if I am wrong to treat girls well. I treat girls well since I have come to be mature, but why do girls always like someone who doesn't care about a girl's feeling and never appreciate the one who respects them? I feel so frustrated and I can't speak out on most days, so I write it down to express my feeling.

Gender influenced participants' journal responses, in which males took a reflective stance as a defensive position, while females took the reflective position as a way of inquiry, to explore how they think about the past and why; hence more inquiries naturally emerge. Patriarchy looms as a hierarchical process in men's dominance over women; within this process, differences light the fuse of competition, discrimination, and denigration versus solidarity and unity (Flynn, 1986, 1990). Dunn (1987) noted a similar situation in which males took another form of resistance: silence. 


\subsection{Resistant Stance}

A struggle with new perspectives occasionally leads to resistance, which may in turn hinder self-development and self-inquiry. Dunn (1987) asserts that students who feel uncomfortable with reading materials, peers and/or pedagogy may throw up barriers: an "ethical" one deflecting challenges to their value system, or a "critical" one that deflects information at loggerheads with their current schemata (pp. 40-41). Whenever gender threatens a reader's social world, one may be forced to confront one's beliefs, deal with one's prejudices, and learn to act responsibly. Frank is a noteworthy example in this class who expressed his strong resistance to reading texts and female counterparts, since both stimulated him to question his biases and assumptions about the society in which he lives.

The most significant experience came near the end of the semester. Throughout three months of research in this classroom, we were involved in talking and reflecting about social issues with emphasis on gender equity. These participants went through stages of development, awareness from intellectualizing issues to seeing them in their own lives. One day, Frank raised the issue of the group's gender dynamics, then expressed deeply tacit beliefs about girls being "prissy," which led to further discussion about the girls' domination in small-group work. The most entrenched resistance came from Frank, who blamed his female counterparts while discussing the film Thelma and Louise (below).

Extract I (Frank, "The Office")

I think the lady must be crazy. Why did she not stay at home and write? Why did she not move in with her husband? Why must she live alone and rent a room for her writing purpose? Many girls like to show independence without boys' help, but that's not right.

Extract J (Frank, Oral interview)

Each time I defended male thoughts, girls in my group always said that I am a big man. It happened to me again and again. Whenever we talked about the movie, I said if Thelma listened to her husband, nothing would happen. She got trouble herself and Linda in my group was very upset with me. She said I am a BIG, BIG man again. This time, I am very angry at her and said that she is a BIG, BIG woman and never respected men.

Frank's anger toward his female counterparts was understandable, but he failed to grasp how the author and his peers meant to challenge his stereotypical view of gender. While his interpretation was valid for him in the moment, he missed the more universal message of the reading text: i.e., that to respect difference can break down stereotypes and bridge seemingly intractable cultural barriers. Such resistance illustrates forms of denial that can seriously hinder self-development and -inquiry. Ruby and Linda were the two who were not afraid to express their ideas, even when presenting a different and more challenging perspective. They keenly focused on gender inequity they saw in reading materials, then connected their generalizations to experiences in a classroom or small-group discussion. Belenky, Clinchy, Goldberger, and Tarule (1997) averred that women who move beyond passivity and acceptance of male domination usually attain more control over their lives. They can see the world from a position of "constructed knowledge," creating their own understanding and recognizing multiple perspectives and alternatives to the status quo.

Similar to Frank's case, Pamela reveals her resistance to both reading material and peers. As hinted by Gilligan (1993), teenage girls watch, listen, and change according to people around them. Gilligan claims that on a daily basis, girls receive lessons on what they can let out and what they must keep in, if they do not want to be morally judged by others, or simply told they are wrong. As a young adult, Pamela, like Gilligan's girls, wants acceptance and recognition by peers, needing positive feedback from teachers and peers alike. Extracts $\mathrm{K}$ and L highlight her situation.

Extract K (Pamela, “The New Dress")

We all know women should love our bodies, don't torture them, don't believe unrealistic advertisements, and don't envy models' ideal appearance. Still, jumping out to a frame of body image is difficult for me. Like Mabel in "The New Dress, " I can not ignore others' judgment on me. Although I tell myself to get rid of those beauty standards, it is hard to accomplish. Knowing is one thing, doing is another. People are not always beautiful, but there are so many other beautiful things around them. This is the biggest problem always bothering us. 'She was a fly, but others were butterfly, beautiful insects.' A female hopes she can become a swan from an ugly duckling. Hence the fly is always around the saucer or in the saucer. It is hard to get ride of the saucer [social standards].

Extract L (Pamela, Oral interview)

Linda is the most influential person in my group discussion, very quick-thinking, and has taken some courses on gender issues. I had not much experience reading this kind of text. It [the text] requires a lot of thinking and I think and think, but I think it's difficult to change male concepts, since this is a male world. At least, to me, it's mission impossible.

When speculation and analytical hypothesis were presented to Pamela, she had chances to integrate her own values, ideas, beliefs, and attitudes and to use these opportunities for development of self. Still, her conventional beliefs play a key role in comprehending and interpreting feminist texts. For Pamela, divergence and differences create opportunities as well as problems in learning, a two-sided coin. Like Frank, she only saw one side, not the side full of potential for 
inquiry, since to confront the other side required her to change, to doubt, and even to inquire further. As presented in Extract L lack of reading experience in the area of gender issues was a prime concern in the process of reading and responding to feminist texts. Some also said during oral interview that reading tension caused by this problem gradually decreased as the course progressed. While speaking, some reported involvement in fulfilling more than one task at a time. That is, they not only reflected on a subject/topic of self-expression but also thought "very hard" to ensure their oral syntax was understandable to others. They felt that "a head has to do many tasks at one time," as Anna stated in her journal. One other major factor actually emanates from the study and merits further discussion. What with girls expected to be "passive," "silent," confirming, submissive, and "veiled," some females' active role in small-group discussion appeared contradictory to certain concepts that most participants knew and to narratives they used.

\section{Extract M (Linda, Oral Interview)}

In this class, we girls can talk freely because we are encouraged to project our voice by the teacher. In other classes, if I talk, or probably talk a little bit too much, I can feel both my male and female classmates looking at me with a very strange eye. I felt like I did something wrong in this class. I found when any male talked, my teacher and classmates felt all right. I asked my classmate, Jane, who is taking the same class with me, and she felt the same way. So I think I am not too sensitive to my classmates' responses. I think "silence is golden" is still a motto to us girls if we want to have a peaceful life.

Atwood (1994) argues that tension arises with regard to gender differences when a deeply held value or belief is challenged. When female participants do not join in discussions, it is assumed that they lack ability and knowledge; when they do, they tend to be disliked and labeled as invaders, particularly if their voices contradict those of male counterparts. This in turn may rob female students of that very self-confidence and motivation they had prior to entering the university. Some females expressed unease about participating in a discussion, particularly one focused on gender and power issues, despite their perception of me. Similarly, the researcher heard males complain of being disrespected and excluded when discussing gender and power. Who felt "empowered" by them? Who benefitted? Frank (Extract I) perceived female classmates as granted privileged voice; Linda as stated in Extract $\mathrm{M}$ was forced into silence by what she saw as males' confrontational and alienating speech style.

\section{Conclusion}

Results from the current study indicate that male and female participants employed four stances to attack feminist texts in different ways. When encountering the parts that participants lacked of background knowledge or experiences or even the parts that they didn't understand, male and female participants responded differently. For female participants not only stated what they did not understand, but also attempted to interpret a part she didn't fully understand, whereas male participants stated their lack of experience or understanding and then disengaged from the text. As for the evaluative stance, both female and male participants exhibited emotional reactions to events, and therefore showed their engagement with the texts. Female participants focused on their emotional reactions to the characters involved in the event, rather than on the event itself. Females' responses revealed empathy more with characters than with the situations, whereas males responded with empathy more toward situations or the events itself rather than about characters. While employing reflective stance, male participants tended to criticize what a character did in a story and then stated that they would act differently; female responses, similarities between characters and self of readers superseded differences. Girls related affectively to characters in a story, identifying and expressing feelings of fear, sadness, pity, or anger, whereas boys in this class only took a reflective stance as a way to defend their voices. Some participants struggled with the concept of gender equity at times and consequently led to resistance. Some expressed strong resistance to reading texts and female counterparts, since both impelled them to question biases and assumptions about a society in which they live. Such types of resistance represent forms of denial that may seriously hinder their self-development and self-inquiry. Many participants' understanding of gender was enhanced by the stories read, small-group discussion, and by relating issues in the texts to their own life, as they experienced gender issues in their classroom. It was recursive (not linear) process in which their behaviors informed their thinking. Their reflection began to modify their behaviors, and reading fortified their understanding. Changing perspective made them more aware of their own feelings, along with the need to rethink what they experienced and learned about themselves vis-à-vis the opposite sex.

\section{Implications}

As with qualitative research, only ten participants were analyzed for the current paper. This limits generalizability of findings, as do four stances delineated herein. Results merit further evaluation of students in larger numbers at various language proficiency levels. Despite the limitations, some implications for pedagogical practice surfaced from this probe.

Reading feminist texts should be viewed from an inquiry perspective with an open-ended list, meaning that the texts can be constantly added to or subtracted from, changed or modified as it is played out within the practice of inquiry. Students have differing needs, interests, perceptions, and interpretations of gender issues; teachers should stand beside 
students and do more with feminist texts in ESL/EFL than merely replicate the power practices of benevolent, helping relations. Gender equity is thus not simply one moral social issue in ESL/EFL but a way of thinking, of teaching, and most importantly, of learning.

If teachers indeed hope to promote a concept of gender equity in ESL/EFL class settings, they should let students feel free to express what they find valuable in their thoughts and experiences; thus, reader-response should not be limited to written reflections. Reading, writing, and talking become mutually supportive learning activities. By the act of response, students adopt a textual, evaluative, reflective or even resistant stance, not only a tool for encouraging personal engagement in reading, but also a method to help them refine their understanding of texts.

It is important for teachers to concern about selecting texts used in classrooms. The texts should have well-rounded male and female characters in which individuals have distinct personalities regardless of their genders. For example, feminist texts can help students recognize gender- stereotypical messages. The combination of traditional and non-traditional texts can spark discussion of how genders are portrayed in different texts that promote gender-neutral attitudes. Moreover, the portray non-traditional gender roles, including boys and men in nurturing or care-giving roles, as well as girls and women in active, leadership roles, provides an important contrast to the commonly popular cultural messages often seen and heard by university students. Hence, the use of appropriate feminist texts must be well-timed as ESL/EFL students construct their views of being adults.

\section{References}

Alcoff, L. (1988). Cultural feminism versus post-structuralism: The identity crisis in feminist theory. Signs, 13, 405-436.

Atwood, J. (1994). Good intentions, dangerous territory: Student resistance in feminist writing classes. Journal of Teaching Writing, 12, 2,125-143.

Barrs, M. (2000). Gender literacy? Language Arts, 77,4, 287-293.

Bantmeier, C. (2003). Does gender make a difference? Passage content and comprehension in second language reading. Reading in a Foreign Language, 15(1), 1-27.

Beach, R. (1994). Adopting multiple stances in conducting literacy research. In R. B. Ruddell, M. R.

Ruddell, \& H. Singer (Eds.), Theoretical models and processes of reading (pp.1203-1119). Newark, Delaware: IRA.

Beach, R. (1997). Critical discourse theory and reader response: How discourses constitute reader stances and social contexts. Reader, 37, 1-26.

Beach, R. (1998). Constructing real and text worlds in responding to literature. Theory into Practice, 37, 3, 176-185.

Berggren, A. (1994). Reading like a woman. In P.P. Schweickart \& E. A. Flynn (Eds.), Reading sites: social difference and reader response (pp.166-188). N.Y.: MLA.

Blenky, M. F., Clinchy, B.M., Goldberger, N. R., \& Tarule, J. M. (1997). Women's ways of knowing: The development of self, voice, and mind, 10th Anniversary Edition. N.Y.: Basic Books, Inc.

Cherland, M. (1993). Gendered readings: Cultural restraints upon response to literature. The New Advocate, 5, 3, 187-198.

Cherland, M. (1994). Private practices: girls reading fiction and constructing identity. Bristol, PA: Taylor \& Francis.

Cherland, M., \& Edelsky, C. (1993). Girls and reading: The desire of agency and the horror of helplessness in fictional encounters. In L. K. Christian-Smith (Ed.), Texts of desire: Essays on fiction, femininity and schooling (pp. 28-44). Washington, D.C.: The Falmer Press.

Cherland, M., \& Harper, H. (2007). Advocacy research in literacy education: seeking higher ground. Mahwah, N. J.: Lawrence Erlbaum Associates.

Chi, F-M. (2006). Teachers' ways of believing, practicing, and changing. Research Report of National Science Council, Taiwan.

Chi, F-M. (2008). Reflection as teaching inquiry. Paper presented at the $33^{\text {rd }}$ Applied Linguistics of Australian Associations (July 4-7), Sydney, Australia.

Cochran, E. P. (1996). Gender and the ESL classroom. TESOL Quarterly, 30, 1, 159-162.

Corcoran, B. (1992). Reader stance: From willed aesthetic to discursive construction. In Joyce Many \& Carole Cox (Eds.). Reader stance and literary understanding (pp. 49-76). Norwood, NJ: Ablex.

Dunn, K. 1987. Feminist teaching: Who are your students? Women's Studies Quarterly, 15, 3-4, 40-46. 
Evans, K. S. (1996). A closer look at literature discussion groups: The influence of gender on student response and discourse. The New Advocate, 9(3), 195-204.

Evans, K. S. (1997). Exploring the complexities of peer-led literature discussions: The influence of gender. In J. R. Paratore \& McCormack, R. L. (Eds.). Peer talk in the classroom: Learning from research (pp. 26-44). Newark, Delware: International Reading Association.

Flynn, E. (1986). Gender and reading. In E. Flynn \& P. Schweickart (Eds.), Gender and reading: Essays on readers, texts, and contexts (pp.267-287). Baltimore: The Johns Hopkins University Press.

Flynn, E. (1990). Composing as a woman. In Susan L. G., \& Isaiah, S. (Eds.), Gender in the classroom: Power and pedagogy (pp.112-126). Urbana and Chicago: University of Illinois Press.

Flynn, E. (1994). "Gender and reading" revisited. In Clifford J., Schilb, J. (Eds.), Writing theory and critical theory (pp.313-318). N.Y.: MLA.

Gilligan, C. (1993). Joining the resistance: Psychology, politics, girls, and women. In L. Weis, \& M. Fine (Eds.), Beyond silenced voices: Class, race, and gender in United States schools (pp.143-168). N.Y.: State

University of New York Press.

Heiskanen, T. (2006). Gender issues in action research: implications for adult education. International Journal of Lifelong Education, 25(5), 519-533.

Krockover, G. H., \& Shepardson, S.D.P. (1995). The missing links in gender equality research. Journal of Research in Science Teaching, 32, 223-224.

Lincoln, Y. S., \& Guba, E. G. (1985). Naturalistic inquiry. Newbury Park, California: Sage Publications..

Lloyd, C. V. (1998). Adolescent girls: Constructing and doing literacy, constructing and doing gender. Reading Research Quarterly, 33, 129-136.

Mackie, A. (1999). Possibilities for feminism in ESL education and research. TESOL Quarterly, 33, 3, 566-573.

Maher, F. A., \& Ward, J. V. (2002). Gender and teaching. Mahwah, J. J.: Lawrence Erlbaum Associates, Inc.

Many, J. (1994). The effects of reader stance on students' personal understanding of literature. In Robert B.

Ruddell., Martha Rapp Ruddell, Harry Singer (Eds.), Theoretical models and processes of reading (pp.653-667). Newark Delaware: IRA.

Many, J. (2001). Handbook of instructional practices for literacy teacher-educators: Examples and reflections from the teaching lives of literacy scholars. Mahwah, N.J.: L. Erlbaum Associates.

Many, J., \& Cox, C. (1992). Reader stance and literary understanding: Exploring the theories, research, and practice. Norwood, NJ: Ablex.

Schenki, A. (1996). Feminist theory and the ESL classroom not just a "Social Issue": Teaching feminist in ESL. TESOL Quarterly, 30, 1, 155-159.

Singh, M. (2008). Factors contributing to reading literacy differences between males and females." International Journal of Learning, 15, 3, 337-344.

Taylor, S. (1993). Transforming the text: Towards a feminist classroom practice. In L. K. Christian-Smith (Ed.), Texts of desire: Essays on fiction, femininity and schooling (pp.126-144). Washington, D.C.: The Falmer Press.

Trousdale, A. M. (1995). I'd rather be normal: A young girl's responses to "feminist" fairy tales. The New Advocate, 8, $3,167-182$.

Wayne, R. (2004). Perspectives on gender. Educational Studies, 35 (2), 175-180.

\section{Appendix 1}

Texts from Susan Cahill's Women and fiction: Short stories by and about women (1975):

Alice Walker's "Everyday Use"

Alice Munro's "The Office"

Texts from Barbara Walker's The Feminist Fairy Tales (1996):

"Princess Questa;" "The Frog Princess," "Little White Riding Hood" 